\title{
A multi-criteria decision making approach for the selection of a flexible packaging equipment
}

\author{
Ciprian Cristea $^{1, *}$, and Maria Cristea $^{1}$ \\ ${ }^{1}$ Technical University of Cluj-Napoca, Faculty of Electrical Engineering, Romania
}

\begin{abstract}
Flexible packaging is one of the fastest growing segments of the packaging industry, combining paper, plastic film and aluminum foil to deliver a broad array of products for food and beverage, personal care products, and pharmaceutical industries. In order to preserve the quality and safety of the product contained in them, there are currently a variety of flexible packaging equipment options available. However their relative costs and performance differ. This study proposes an application of a ranking methodology to assess a selection of the most suitable flexible packaging equipment. The adequate criteria in the selection of equipment have been identified, and the considered options are assessed, considering the decision maker's preferences and existing constraints. The options are ranked in terms of their suitability for selecting equipment by using the Electre III method. The results obtained from the simulation experiment highlight the effectiveness of the model in outranking different options in the process of equipment selection.
\end{abstract}

\section{Introduction}

In the contemporary competitive manufacturing environment, to cope with increasingly high consumer expectations regarding quality products and services, shortening of product life cycles, low profit margins, short lead-times and rapid innovation, organizations have to invest and improve their production facilities. Technology is one of the most important resources of companies that have to take into account any opportunity to optimize their manufacturing processes. In order to enhance their production and productivity, practitioners and academics have come to the same conclusion: the firms have to invest in new technology and acquire latest pieces of equipment. Despite the fact that innovation and investment in new technology involve high costs, these represent some of the few sources of growth, being a positive relationship between the development of an enterprise and the equipment investment rates [1]. The adequate equipment selection is time consuming and involves a complex decision. In this process, multiple decision makers, with various expertise and perspectives, are frequently implied and have to deal with ambiguity and uncertainty, such as undifferentiated alternatives, incomplete information and inadequate understanding [2].

The global packaging market stood at $\$ 812$ billion in 2014 , while sales from packaging industry are projected to increase by 3.3 percent in real terms for 2015 to $\$ 839$ billion, and

\footnotetext{
*Corresponding author: ciprian.cristea@emd.utcluj.ro
} 
an annual growth of $3.5 \%$ per year to 2020 is forecasted, with sales to reach $\$ 997$ billion by 2020 [3]. In order to cope with the growing demand and the huge interest in new types of packaging and the latest film technology, the companies have to invest in the latest equipment technologies for further developments in different sectors.

Flexible packaging is probably the most economical method to package, preserve and distribute a broad array of products for food and beverage, personal care products, pharmaceuticals and other products that need extended shelf life. In the contemporary retail market, more than two-thirds of the purchasing decisions are made in the store, when standing in front of the shelf, frequently preferring this to other forms of communication. The consumers decide within seconds whether they will purchase a product, so packaging has to absolve also persuasive functions, transfer emotions and sensual impressions [4].

The selection of new equipment is a time-consuming and complex process that necessitates experience and advanced knowledge. For an adequate assessment the decision maker may require a large amount of data to be analyzed and many factors to be taken into account. In order to select the most appropriate equipment among others, the decision-maker should be an expert or at least be very familiar with its specifications [5]. The middle and upper management have a ninety-four percent involvement in authorization for final selection, while the remaining six percent belongs to engineering staff [6].

The equipment selection problem received a lot of attention recently. Multiple studies have been performed dealing with this subject, such as analytical hierarchy process (AHP) [7], artificial neural network [8], Elimination and Choice Expressing Reality (ELECTRE) [9], multiobjective optimization on the basis of ratio analysis (MOORA) [10], fuzzy AHP [11], combination of AHP and Preference Ranking Organisation Method for Enrichment Analysis (PROMETHEE) [12], fuzzy Techniques for Order Performance by Similarity to Ideal Solution (TOPSIS) [13], fuzzy AHP and Grey Relational Analysis (GRA) [14], VIsekriterijumsko KOmpromisno Rangiranje (VIKTOR) [15], Step-wise Weight Assessment Ratio Analysis (SWARA) and COmplex PRoportional ASsessment of alternatives with Grey relations (COPRAS-G) [16].

The rest of the paper is organized as follows: in the second section the methodology of multiple criteria decision making is presented. The third section describes the case study based action research for the equipment performance evaluation within a firm working in the field of flexible packaging production. The alternatives (equipment), evaluation criteria and decision making's preferences are described in this section. The results of the computational experiments are presented in the fourth section and, finally, the last section summarizes the conclusions.

\section{Methodology}

The multiple criteria decision making methods are used for solving complex problems featuring high unpredictability, various forms of data and information, conflicting objectives, multi interests and perspectives, and the accounting for complex and evolving socioeconomic and biophysical systems [17]. The selection of optimal equipment from a finite number of alternative equipment on the basis of many different and conflicting attributes is a multi-criteria decision making problem. In order to select the optimum equipment, practitioners and academics have found that the price of the equipment shouldn't be the overriding determinant. The analysis of several alternative solutions involves the assessment based on diverse quantitative and qualitative criteria. Frequently, these goals are in conflict, so that solutions differ from each other in many features. Therefore, there is no single solution that optimizes all criteria simultaneously, and there is no exclusive criterion that describes the consequences of each alternative solution correspondingly. Multiple criteria decision making methods use mathematical models that assess alternative scenarios of equipment, 
taking into account both their objective characteristics and the preferences of the decision makers [18].

Among the existing methods, the ELECTRE III was chosen for its ability to deal with inaccurate, imprecise, uncertain data, inevitable to complex processes in human decision [19]. This method is based on the application of the outranking relation, in ranking a finite set of alternatives from the best to the worst, on the basis of using a set of evaluation criteria [20].

The ELECTRE III method algorithm comprises the following three phases [21-23]:

1) Establishing a set of data - a set of alternatives and a family of criteria used for comparison are defined, followed by the performance matrix development. In order to produce outranking relations with an allowance for data uncertainly, the indifference $\left(q_{i}\right)$, preference $\left(p_{i}\right)$, and veto $\left(v_{i}\right)$ threshold, as well as criteria weight indexes $\left(w_{i}\right)$ are defined.

2) Construction of the outranking relations - the possible alternative solutions are pairwise compared and each pairwise comparison is characterized by an outranking relation. The outranking relation is built on the basis of the concordance and the discordance matrices. The concordance index for each pair of alternatives $A$ and $B$ is determined by comparing the performances of both alternatives for every criterion. The concordance index shows the truth of the statement " $A$ outranks $B$ ". The value of concordance index is between 0 and 1 , the full truth of the assertion being indicated by a value of 1 , while a value of 0 highlights that the statement is false. The concordance index is defined as follows [24]:

$$
\mathrm{C}(\mathrm{A}, \mathrm{B})=\frac{1}{\mathrm{~W}} \cdot \sum_{\mathrm{i}=1}^{\mathrm{n}} \mathrm{w}_{\mathrm{i}} \cdot \mathrm{c}_{\mathrm{i}}(\mathrm{A}, \mathrm{B})
$$

where:

$W-$ sum of all weights of criteria $\left(W=\sum_{i=1}^{n} w_{i}\right)$;

$w$ - weight of criterion $i$

$n$ - number of criteria;

$c_{i}(A, B)$ - concordance index over alternatives $A$ and $B$ with respect to the criterion $i$;

$$
c_{i}(A, B)=\left\{\begin{array}{l}
1, \text { if } q_{i}\left(f_{i}(A)\right) \geq f_{i}(B)-f_{i}(A) \\
\frac{p_{i}\left(f_{i}(A)\right)+f_{i}(A)-f_{i}(B)}{p_{i}\left(f_{i}(A)\right)-q_{i}\left(f_{i}(A)\right)} \\
0, \text { if } p_{i}\left(f_{i}(A)\right) \leq f_{i}(B)-f_{i}(A)
\end{array}, \text { if } p_{i}\left(f_{i}(A)\right)>f_{i}(B)-f_{i}(A)>q_{i}\left(f_{i}(A)\right)\right.
$$

where:

$f_{i}(A)$ - performance of alternative $A$ based on the criterion $i$

$f_{i}(B)$ - performance of alternative $B$ based on the criterion $i$;

$q_{i}$ - indifference threshold for the criterion $i$;

$p_{i}$ - preference threshold for the criterion $i$.

The concordance index for each pair of alternatives $A$ and $B$ is determined by comparing the performances of both alternatives for every criterion.

The discordance index for each pair of alternatives $A$ and $B$ is determined by comparing the performances of both alternatives for every criterion. The strength of the evidence against the statement " $A$ outranks $B$ " is evaluated by the discordance index. If the difference of performances between the alternative $A$ and $B$, on any criterion $i$, is higher than the veto threshold $v_{i}$, it can be overruled. The discordance index for each criterion $i$ is given by equation (3) [25]. 


$$
D_{i}(A, B)=\left\{\begin{array}{l}
0, \text { if } p_{i}\left(f_{i}(A)\right) \geq f_{i}(B)-f_{i}(A) \\
\frac{f_{i}(B)-f_{i}(A)-p_{i}\left(f_{i}(A)\right)}{v_{i}\left(f_{i}(A)\right)-p_{i}\left(f_{i}(A)\right)} \\
1, \text { if } v_{i}\left(f_{i}(A)\right) \leq f_{i}(B)-f_{i}(A)
\end{array}, \text { if } v_{i}\left(f_{i}(A)\right)>f_{i}(B)-f_{i}(A)>p_{i}\left(f_{i}(A)\right)\right.
$$

where:

$v_{i}$ - veto threshold for the criterion $i$;

The outranking relation is expressed by the degree of credibility. The credibility index $S(A, B)$ is defined as follows [22]:

$$
\mathrm{S}(\mathrm{A}, \mathrm{B})=\left\{\begin{array}{l}
\mathrm{C}(\mathrm{A}, \mathrm{B}), \text { if } \mathrm{C}(\mathrm{A}, \mathrm{B}) \geq \mathrm{D}_{\mathrm{i}}(\mathrm{A}, \mathrm{B}) \forall \mathrm{i} \\
\mathrm{C}(\mathrm{A}, \mathrm{B}) \cdot \prod_{\mathrm{i} \in \mathrm{J}(\mathrm{A}, \mathrm{B})} \frac{\left(1-\mathrm{D}_{\mathrm{i}}(\mathrm{A}, \mathrm{B})\right)}{(1-\mathrm{C}(\mathrm{A}, \mathrm{B}))}, \text { otherwise }
\end{array}\right.
$$

where:

$J(A, B)$ - the set of criteria for which $D_{i}(A, B)>C(A, B)$.

The credibility matrix is given by the degrees of credibility.

3) Exploitation of the outranking relations - in order to rank the alternatives, a distillation procedure is used. A descending and an ascending preorder can be obtained by using this procedure. The final ranking is acquired by combining these preorders. The ranking matrix contains the aggregation of the above mentioned preorders. There are the following cases [22], [26]:

a) If alternative $A$ is higher ranked than alternative $B$ in both distillations or $A$ is better than $B$ in one distillation and has the same position in the other one, then variant $A$ is better than variant $B: A P+B$;

b) If variant $A$ is higher ranked than variant $B$ in one distillation but $B$ is better ranked than $A$ the other distillation, then $A$ is incomparable to $B: A R B$;

c) If alternative $A$ has the same position in the ranking system than alternative $B$ in both distillations, then variant $A$ is indifferent to variant $B$ : $A$ I $B$;

d) If variant $A$ is lower ranked than variant $B$ in both distillations or $A$ is lower ranked than $B$ in one distillation and has the same rank in the other distillation, then $A$ is worst than $B$ : $A P-B$.

The final ranking is achieved by summing the number $\mathrm{P}+$ for each alternative.

\section{Case study}

In order to demonstrate and validate the application of the above mentioned multiple criteria decision making method for solving the equipment selection problem, a case study conducted in collaboration with the management of a leading company working in the field of flexible packaging production is presented.

This case study deals with the equipment selection among a set of seven candidates (Sigma, Tau, Upsilon, Phi, Chi, Psi and Omega), according to a set of requirements indicated by the decision makers. The assessment was performed by managers representing different corporate functions (engineering, manufacturing, sales, and finance departments) whose different points of view have to be comprised in the model. In order to identify the suitable criteria, weights of criteria, and the rates of the evaluated equipment, the decision makers were interviewed. The weights of the criteria and the value of thresholds are presented in table 1 . 
Table 1. Thresholds and criteria weights.

\begin{tabular}{|c|c|c|c|c|}
\hline Criteria & Indifference $q$ & Preference $p$ & Veto $v$ & Weights \\
\hline $\mathrm{C}_{\mathrm{I}}$ & 0.2 & 0.4 & 0.6 & 0.14 \\
\hline $\mathrm{C}_{\text {II }}$ & 0.15 & 0.5 & 0.65 & 0.08 \\
\hline $\mathrm{C}_{\text {III }}$ & 0.1 & 0.3 & 0.4 & 0.06 \\
\hline $\mathrm{C}_{\text {IV }}$ & 0.2 & 0.3 & 0.5 & 0.05 \\
\hline $\mathrm{C}_{\mathrm{v}}$ & 0.1 & 0.3 & 0.6 & 0.02 \\
\hline $\mathrm{C}_{\mathrm{VI}}$ & 0.1 & 0.3 & 0.5 & 0.03 \\
\hline $\mathrm{C}_{\text {VII }}$ & 0.15 & 0.25 & 0.35 & 0.02 \\
\hline $\mathrm{C}_{\text {VIII }}$ & 0.1 & 0.2 & 0.6 & 0.02 \\
\hline $\mathrm{C}_{\text {IX }}$ & 0.2 & 0.3 & 0.7 & 0.03 \\
\hline $\mathbf{C}_{\mathbf{x}}$ & 0.1 & 0.15 & 0.3 & 0.05 \\
\hline $\mathrm{C}_{\mathrm{XI}}$ & 0.2 & 0.4 & 0.6 & 0.02 \\
\hline C XII & 0.2 & 0.3 & 0.5 & 0.02 \\
\hline $\mathbf{C}_{\text {XIII }}$ & 0.1 & 0.15 & 0.35 & 0.03 \\
\hline $\mathrm{C}_{\text {XIV }}$ & 0.2 & 0.4 & 0.7 & 0.02 \\
\hline $\mathrm{C}_{\mathrm{Xv}}$ & 0.1 & 0.2 & 0.6 & 0.04 \\
\hline $\mathrm{C}_{\text {XVI }}$ & 0.3 & 0.45 & 0.6 & 0.02 \\
\hline $\mathrm{C}_{\text {XVII }}$ & 0.15 & 0.25 & 0.4 & 0.01 \\
\hline C XVIII & 0.2 & 0.3 & 0.4 & 0.01 \\
\hline $\mathrm{C}_{\text {XIX }}$ & 0.2 & 0.4 & 0.6 & 0.03 \\
\hline $\mathbf{C}_{\mathrm{Xx}}$ & 0.1 & 0.3 & 0.6 & 0.04 \\
\hline $\mathrm{C}_{\mathrm{XXI}}$ & 0.1 & 0.2 & 0.45 & 0.03 \\
\hline $\mathrm{C}_{\text {XXII }}$ & 0.2 & 0.3 & 0.4 & 0.02 \\
\hline $\mathrm{C}_{\text {XXIII }}$ & 0.2 & 0.4 & 0.6 & 0.03 \\
\hline C xxIV & 0.15 & 0.25 & 0.4 & 0.01 \\
\hline $\mathrm{C}_{\mathrm{XXV}}$ & 0.2 & 0.35 & 0.5 & 0.01 \\
\hline $\mathrm{C}_{\text {XXVI }}$ & 0.1 & 0.3 & 0.5 & 0.01 \\
\hline $\mathrm{C}_{\text {XXVII }}$ & 0.15 & 0.4 & 0.6 & 0.03 \\
\hline C XXVIII & 0.1 & 0.2 & 0.3 & 0.01 \\
\hline$C_{\text {XxIX }}$ & 0.3 & 0.5 & 0.7 & 0.02 \\
\hline C xxx & 0.2 & 0.4 & 0.6 & 0.02 \\
\hline $\mathbf{C}_{\text {XXXI }}$ & 0.2 & 0.3 & 0.5 & 0.03 \\
\hline $\mathrm{C}_{\text {XXXII }}$ & 0.1 & 0.2 & 0.6 & 0.04 \\
\hline
\end{tabular}

The decision makers have proposed thirty-two criteria $\left(\mathrm{C}_{\mathrm{I}}\right.$ to $\left.\mathrm{C}_{\mathrm{XXXII}}\right)$ in order to perform a complete evaluation of the equipment. The determined criteria are presented as follows: price $\left(\mathrm{C}_{\mathrm{I}}-\right.$ [Euro] $)$, quality $\left(\mathrm{C}_{\mathrm{II}}-\right.$ [points $\left.]\right)$, maximum speed $\left(\mathrm{C}_{\mathrm{III}}-[\mathrm{lm} / \mathrm{min}]\right)$, maximum print width $\left(\mathrm{C}_{\mathrm{IV}}-[\mathrm{mm}]\right)$, flexographic printing repeat $\left(\mathrm{C}_{\mathrm{V}}-\right.$ [points] $)$, maximum web width and web dimensions $\left(\mathrm{C}_{\mathrm{VI}}-\right.$ [points] $)$, material diversity $\left(\mathrm{C}_{\mathrm{VII}}-\right.$ [points $\left.]\right)$, number of printing decks $\left(\mathrm{C}_{\mathrm{VIII}}-[\right.$ points $\left.]\right)$, drying system and UV curing system $\left(\mathrm{C}_{\mathrm{IX}}-\right.$ [points] $)$, change over time $\left(\mathrm{C}_{\mathrm{X}}\right.$ - [points]), central impression drum cylinder or in line cylinders $\left(\mathrm{C}_{\mathrm{XI}}-\right.$ [points] $)$, temperature controller $\left(\mathrm{C}_{\mathrm{XII}}-\right.$ [points]), transmission type and drive system ( $\mathrm{C}_{\mathrm{XIII}}-$ [points]), computerized setting of print decks $\left(\mathrm{C}_{\mathrm{XIV}}-\right.$ [points] $)$, automatic module register $\left(\mathrm{C}_{\mathrm{XV}}-\right.$ [points]), production controls and job chart $\left(\mathrm{C}_{\mathrm{XVI}}-\right.$ [points]), reverse printing $\left(\mathrm{C}_{\mathrm{XVII}}-\right.$ [points]), turret unwinder and rewinder capacity $\left(\mathrm{C}_{\mathrm{XVIII}}-[\right.$ points] $)$, automatic pressure module ( $\mathrm{C}_{\mathrm{XIX}}-$ [points]), automatic defect detection system $\left(\mathrm{C}_{\mathrm{XX}}-\right.$ [points]), delivery terms $\left(\mathrm{C}_{\mathrm{XXI}}-[\right.$ points $\left.]\right)$, delivery time $\left(\mathrm{C}_{\mathrm{XXII}}-[\right.$ months $\left.]\right)$, terms of payment $\left(\mathrm{C}_{\mathrm{XXIII}}-[\right.$ points $\left.]\right)$, assembly and start-up of the machine $\left(\mathrm{C}_{\mathrm{XXIV}}-\right.$ [points]), machine acceptance tests $\left(\mathrm{C}_{\mathrm{XXV}}-\right.$ [points]), service project manager ( $\mathrm{C}_{\mathrm{XXVI}}-$ [points]), warranty and after warranty service 
( $\mathrm{C}_{\mathrm{XXVII}}-[$ points] $)$, corona treatment systems $\left(\mathrm{C}_{\mathrm{XXVIII}}-[\right.$ points] $)$, job types and runs $\left(\mathrm{C}_{\mathrm{XXIX}}\right.$ - [points]), plate-cylinder assembly $\left(\mathrm{C}_{\mathrm{XXX}}-\right.$ [points]), video web inspection $\left(\mathrm{C}_{\mathrm{XXXI}}-\right.$ [points]), ink management and doctor blade chamber ( $\mathrm{C}_{\mathrm{XXXII}}-$ [points]).

Table 2 indicates the performance of all the alternatives to be evaluated with respect to identified criteria that meet managers' expectations.

Table 2. Performance matrix.

\begin{tabular}{|c|c|c|c|c|c|c|c|}
\hline Criteria & Sigma & Tau & Upsilon & Phi & Chi & Psi & Omega \\
\hline $\mathrm{C}_{\mathrm{I}}$ & 1800000 & 900000 & 1600000 & 1650000 & 1400000 & 1700000 & 1300000 \\
\hline $\mathrm{C}_{\text {II }}$ & 90 & 50 & 70 & 95 & 80 & 85 & 75 \\
\hline $\mathbf{C}_{\text {III }}$ & 400 & 300 & 200 & 360 & 400 & 350 & 380 \\
\hline $\mathrm{C}_{\text {IV }}$ & 1270 & 1100 & 850 & 660 & 1200 & 1250 & 1270 \\
\hline $\mathrm{Cv}_{\mathrm{v}}$ & 53.33 & 53.33 & 56.67 & 56.67 & 53.33 & 53.33 & 50 \\
\hline $\mathrm{C}_{\text {VI }}$ & 72 & 56 & 40 & 48 & 64 & 72 & 68 \\
\hline $\mathrm{C}_{\text {VII }}$ & 45 & 40 & 45 & 47.5 & 42.5 & 45 & 42.5 \\
\hline $\mathrm{C}_{\text {VIII }}$ & 8 & 8 & 8 & 8 & 8 & 8 & 8 \\
\hline $\mathrm{C}_{\text {IX }}$ & 32.73 & 27.27 & 21.82 & 25.45 & 29.09 & 32.73 & 30.91 \\
\hline $\mathrm{C}_{\mathrm{X}}$ & 23.75 & 17.5 & 20 & 23.75 & 17.5 & 22.5 & 22.5 \\
\hline $\mathrm{C}_{\mathrm{XI}}$ & 47.5 & 40 & 30 & 35 & 45 & 45 & 45 \\
\hline $\mathrm{C}_{\mathrm{XII}}$ & 11.25 & 9.38 & 8.75 & 10.63 & 10 & 10.63 & 10.63 \\
\hline $\mathrm{C}_{\mathrm{XIII}}$ & 15.83 & 12.5 & 13.33 & 15 & 14.17 & 15 & 15 \\
\hline $\mathrm{C}_{\mathrm{XIV}}$ & 38 & 28 & 30 & 34 & 30 & 34 & 34 \\
\hline $\mathrm{C}_{\mathrm{xv}}$ & 60 & 46.67 & 46.67 & 53.33 & 53.33 & 56.67 & 56.67 \\
\hline $\mathrm{C}_{\mathrm{XVI}}$ & 21.25 & 17.5 & 17.5 & 21.25 & 20 & 20 & 20 \\
\hline $\mathrm{C}_{\mathrm{XVII}}$ & 50 & 50 & 80 & 90 & 50 & 60 & 50 \\
\hline $\mathrm{C}_{\text {XVIII }}$ & 40 & 35.56 & 31.11 & 37.78 & 35.56 & 40 & 40 \\
\hline $\mathrm{C}_{\mathrm{XIX}}$ & 28.33 & 23.33 & 23.33 & 25 & 25 & 26.67 & 28.33 \\
\hline $\mathrm{C}_{\mathrm{xx}}$ & 9 & 7 & 7.5 & 8.5 & 8 & 9 & 8.5 \\
\hline $\mathrm{C}_{\mathrm{XXI}}$ & 17.5 & 20 & 22.5 & 18.75 & 21.25 & 20 & 20 \\
\hline $\mathrm{C}_{\text {XXII }}$ & 8 & 6 & 6 & 7 & 5 & 7 & 7 \\
\hline C XXIII & 14 & 14 & 18 & 15 & 18 & 15 & 14 \\
\hline C xxIV & 30.91 & 25.45 & 21.82 & 30.91 & 27.27 & 29.09 & 32.73 \\
\hline $\mathrm{C}_{\mathrm{XXV}}$ & 48.39 & 48.39 & 45.16 & 54.84 & 45.16 & 51.61 & 51.61 \\
\hline $\mathrm{C}_{\mathrm{XXVI}}$ & 11.43 & 8.57 & 8.57 & 12.86 & 10 & 10.71 & 10.71 \\
\hline $\mathrm{C}_{\text {XXVII }}$ & 10 & 8.13 & 7.5 & 10.63 & 8.75 & 9.38 & 10 \\
\hline $\mathrm{C}_{\text {XXVIII }}$ & 9.47 & 7.37 & 7.37 & 8.95 & 7.37 & 8.95 & 9.47 \\
\hline$C_{\text {XXIX }}$ & 21.25 & 17.5 & 20 & 22.5 & 18.75 & 20 & 20 \\
\hline $\mathrm{C}_{\mathrm{xxx}}$ & 20 & 16.67 & 15.56 & 20 & 18.89 & 20 & 18.89 \\
\hline $\mathrm{C}_{\mathrm{XXXI}}$ & 15.83 & 11.67 & 12.5 & 14.17 & 12.5 & 14.17 & 15 \\
\hline C XxxII & 19 & 14 & 15 & 16 & 15 & 17 & 17 \\
\hline
\end{tabular}

\section{Results}

The implementation of ELECTRE III method to the equipment selection problem at a leading company working in the field of flexible packaging production is, practically speaking, not feasible in the absence of specialized software. This problem and the complexity of the decision making process are amplified by the large number of criteria a high performance equipment has to meet for a proper assessment. To address this difficulty, we have developed a software, executable within the Microsoft Windows operation system, based on the ELECTRE III method algorithm, capable of performing the computational experiments. The decision support system has been developed as a Windows Forms application, and has been 
implemented using .NET and Visual Studio 2015. The language used is C\#, which provides full support for object-oriented programming, allowing for the key concepts to be expressively and concisely represented. It uses inheritance, containment, encapsulation and polymorphism in order to provide much greater flexibility. Further development could consist in creating an automated test framework to ease the effort of making changes and adding new features. Another improvement could be to isolate the business logic into a framework which could power separate front ends, such as mobile devices, web applications, or other applications which might import the functionality either as a package or a DLL.

In order to indicate which the most appropriate flexible packaging equipment solution is, the user of the application has to define a set of alternatives and a set of comprehensive criteria with which to compare them by selecting File/New from the menu bar. Each criterion has an increasing preference direction if the objective is to maximize the criterion, like for example the maximum speed, or decreasing preference direction if the goal is to minimize the criterion, like for instance the change over time. The performance of the alternatives to be assessed with respect to identified criteria is depicted via Input/Performance Matrix from the menu bar. The preference parameters for each criterion are depicted via Input/Thresholds from menu bar. The preference parameters and the performance of the alternatives were entered in the application according to the experts' options shown in tables 1-2. Having established the input data, we may continue to the calculation of the rankings by selecting Action/Compute from the menu bar. Following the performed computational experiments, intermediate results (the concordance matrix, the discordance matrix and the credibility matrix) were acquired, accessible via Action from the menu bar. Figure 1 presents the concordance matrix computed by the application.

\begin{tabular}{|c|c|c|c|c|c|c|c|c|c|c|c|}
\hline \multicolumn{12}{|c|}{ 口 } \\
\hline \multicolumn{12}{|c|}{ Action } \\
\hline \multicolumn{12}{|c|}{ Data computed } \\
\hline \multicolumn{2}{|c|}{ Final Ranking } & Performance Matrix & Thresholds & Concordance Matrix & Discordance Matrix & Credibilty Matrix & \multicolumn{2}{|c|}{ Distillation - Descending } & Distillation - Ascending & \multicolumn{2}{|l|}{ Final Matrix } \\
\hline & & & Sigma & Tau & Upsilon & Phi & Chi & Psi & Omega & & \\
\hline \multirow[t]{7}{*}{ b } & Sigma & 1 & & $0.837142857142 \ldots$ & $0.937142857142 \ldots$ & $0.988744531933 \ldots$ & $0.921587301587 \ldots$ & $0.982142857142 \ldots$ & ... $0.932698412698 . .$. & & \\
\hline & Tau & & $0.551016950993 \ldots$ & 1 & $0.869642857142 \ldots$ & $0.684368239315 \ldots$ & $0.791558162940 \ldots$ & 0.646302471048 & ... $0.603732975574 \ldots$ & & \\
\hline & Upsilon & & $0.483991893449 \ldots$ & $0.693040473751 \ldots$ & 1 & $0.714833182201 \ldots$ & $0.776197192277 \ldots$ & $0.622156429168 \ldots$ & .. $0.645249866509 \ldots$ & & \\
\hline & Phi & & $0.830108930029 \ldots$ & 0.8 & $0.926060606060 \ldots$ & 1 & $0.880952380952 \ldots$ & $0.885613247263 \ldots$ & ... $0.898582229819 \ldots$ & & \\
\hline & Chi & & $0.842195862891 \ldots$ & 0.89 & $0.947142857142 \ldots$ & $0.903389115525 \ldots$ & 1 & $0.912916666666 \ldots$ & ... $0.921644664466 \ldots$ & & \\
\hline & Psi & & $0.980084033613 \ldots$ & 0.86 & 0.9825 & $0.984962651727 \ldots$ & $0.970000000000 \ldots$ & 1 & $0.975294117647 \ldots$ & & \\
\hline & Omega & & $0.981512605042 \ldots$ & $0.924615384615 \ldots$ & $0.966302857142 \ldots$ & $0.954955985060 \ldots$ & $0.970000000000 \ldots$ & $0.995000000000 \ldots$ & $\begin{array}{ll}\ldots . & 1\end{array}$ & & \\
\hline
\end{tabular}

Fig. 1. Concordance matrix.

Analyzing Figure 1, one may state that there are few arguments that alternative Upsilon is at least as good as alternative Sigma $\left(\mathrm{C}_{\text {(Upsilon, Sigma) }}=0.48\right)$, while there are some high chances that equipment Sigma is at least as good as equipment Upsilon $\left(\mathrm{C}_{\text {(Sigma, Upsilon) }}=0.93\right)$. Following the performed computational experiments, two pre-classifications were obtained. The results from the partial pre-classifications are aggregated into the ranking matrix, depicted in Figure 2. The final ranking of the alternatives is acquired by summing up the number of $\mathrm{P}+$ from the ranking matrix, for each variant. 


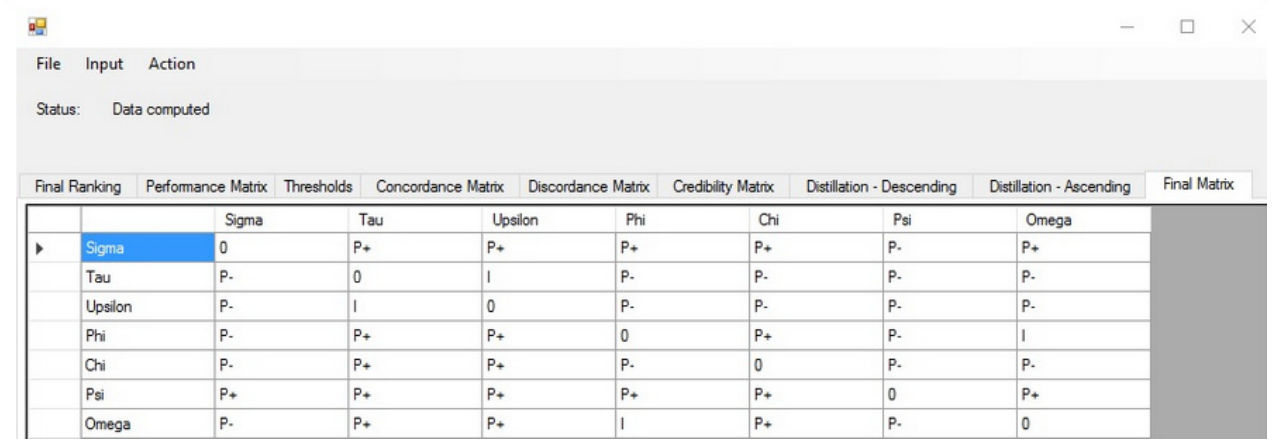

Fig. 2. Ranking matrix.

It can be noticed that equipment Psi got preference over the others, followed by alternative Sigma. The equipment at the third best position were Phi and Omega, being no preference between them, followed by alternative Chi. Finally, the variants Tau and Upsilon got the worst evolution according to the criteria analyzed.

\section{Conclusions}

The growth of the flexible packaging industry has led to an increased need for having and using proper selection of new equipment. The selection process is vital for optimizing performance and productivity, and necessitates the evaluation of various equipment variants based on different criteria.

A practical application of a multiple criteria decision making methods, namely the ELECTRE III method, is proposed in this study to deal with the decision making situation of the equipment selection in industrial environments considering both quantitative and qualitative attributes. The application proposed in this paper helps the decision makers from a company working in the field of flexible packaging production in ranking equipment. Seven equipment have been identified and evaluated according to thirty two criteria that met decision maker's expectations. The final ranking of the equipment was achieved by running the software with the collected data. The results reveal that ELECTRE III method may be a very useful tool to support managers from the flexible packaging industry in facing the problem of selecting suitable equipment for their particular applications.

\section{References}

1. S. Vranakis, P. Chatzoglou, JIEM 7, 24 (2014)

2. B. S. Ahn, K. S. Park, C. H. Han, J. K. Kim, Eur. J. Oper. Res. 125, 9 (2000)

3. Smithers Pira, The Future of Global Packaging to 2020, (2015)

4. D. Aloini, R. Dulmin, V. Mininno, Expert Syst. Appl. 41, 9 (2014)

5. Z. Ayag, R.G. Ozdemir, Int. J. Prod. Econ. 140, 7 (2012)

6. W. Gerrard, Proceedings of $4^{\text {th }}$ National Conference on Production Research 7, (1988)

7. S. Chakraborty, D. Banik, Int. J. Adv. Manuf. Tech. 28, 9 (2006)

8. M. Alberti, J. Ciurana, C. Rodriguez, T. Ozel, J. Intell. Manuf. 22, 15 (2011)

9. C.M. Balaji, et al., Proceedings of the IEEE international conference on automation science and engineering, 6 (2009)

10. S. Chakraborty, Int. J. Adv. Manuf. Tech. 54, 12 (2011)

11. O. Duran, J. Aguilo, Expert Syst. Appl. 34, 8 (2008)

12. M. Dag deviren, J. Intell. Manuf. 19, 10 (2008) 
13. M. Yurdakul, Y.T. Ic, J. Mater. Process. Tech. 209, 8 (2009)

14. A. Samvedi, V. Jain, F.T.S. Chan, Int. J. Prod. Res. 50, 11 (2011)

15. P. Chatterjee, V.M. Athawale, S. Chakraborty, Robot. CIM-INT Manuf. 26, 7 (2010)

16. M. H. Aghdaie, S. Hashemkhani Zolfani,E.K. Zavadskas, Eng. Econ. 24, 13 (2013)

17. J.J. Wang, Y.Y. Jing, C.F. Zhang, J.H. Zhao, Renew. Sust. Energ. Rev. 13, 16 (2009)

18. A. Papadopoulos, A. Karagiannidis, Omega 36, 11 (2008)

19. C.E.D. Infante et all., J. Clean. Prod. 52, 12 (2013)

20. M.K. Janiaka, J. Żakb, Transport. Res. Proced. 3, 10 (2014)

21. J. Zak, S. Weglinski, Transport. Res. Proced 3, 10 (2014)

22. C. Giannoulis, A. Ishizaka, Decis. Support Syst. 48, 10 (2010)

23. M. Cristea, C. Cristea, Proceedings of the Annual Sessions of Scientific Papers "IMT Oradea", 6 (2016)

24. M.S. Pishvaee, R.Z. Farahani, W. Dullaert, Comput. Oper. Res. 37, 13 (2010)

25. J. Figueira, et al., Multiple Criteria Decision Analysis: State of the Art Surveys, (Springer, Berlin, 2005)

26. G.-H. Tzeng, J.-J. Huang, Multiple Attribute Decision Making: Methods and Applications, (CRC Press, Boca Raton, 2011) 